\title{
Oxygen as a Torrefaction Control Parameter
}

\author{
Kees Bourgonje $^{1}$, Hubert J. Veringa ${ }^{1}$, David M.J. Smeulders ${ }^{1} \&$ Jeroen A. van Oijen $^{1}$ \\ ${ }^{1}$ Eindhoven University of Technology, department of Mechanical Engineering, Eindhoven, Netherlands \\ Correspondence: Kees Bourgonje, Eindhoven University of Technology, department of Mechanical Engineering, \\ 5600 MB Eindhoven, Netherlands. Tel: 31-040-247-9111. E-mail: kees.bourgonje1982@gmail.com
}

Received: January 11, 2017

Accepted: February 16, 2017

Online Published: March 30, 2018

doi:10.5539/eer.v8n1p18

URL: https://doi.org/10.5539/eer.v8n1p18

\begin{abstract}
To speed up the torrefaction process in traditional torrefaction reactors, in particular auger reactors, the temperature of the reactor is substantially higher than the required torrefaction process temperature. This is due to the low heat conductivity of biomass. Unfortunately, the off-gas characteristics of biomass are very sensitive in the temperature window of $180-300^{\circ} \mathrm{C}$ which can cause a thermal runaway situation in which the process temperature exceeds the intended level. Due to this very sensitive temperature dependence of biomass pyrolysis and its accompanying gas production, a potential solution is to inject small amounts of air directly into the torrefaction reactor. It is found experimentally that this air injection can regulate the temperature of the biomass very rapidly compared to traditional temperature regulation by changing the reactor wall temperature. With this new torrefaction temperature control method, thermal runaway situations can be avoided and the temperature of the biomass in the reactor can be regulated better. Experiments with large beech wood samples show that the torrefaction reaction rate and the temperature in the core of the sample depend on the amount of injected air. Since the flow of combustible gasses (torr-gas) originating from the torrefaction process is very sensitive to temperature, the heat production by combusting the torr-gas can be controlled to some extent. This will result in both a more homogeneous torrefied product as well as a more stable processing of varying biomass types in large-scale torrefaction systems.
\end{abstract}

Keywords: heating value of ablated torr-gas, large particle torrefaction, oxygen as control parameter

\section{Introduction}

In recent years the influence of oxygen on the torrefaction process has been studied at small scale (Congwei Wang, 2013), (Ajmia Chouchene M. J., 2010), bench scale (Shazleen Saadon, 2014) (Yoshimitsu Uemura, 2013) (Lam, 2016) and pilot scale (Joshi, 2015). The main focus of these experiments was on safety (maximum oxygen concentration before ignition) and economizing (solid yield and its properties e.g. corresponding Higher Heating Value (HHV)) as well as the identification of gaseous product species. Since an inert sweepgas like $\mathrm{N}_{2}$ is rather expensive compared to air/flue gasses, torrefaction experiments were only done on pilot scale to determine the maximum oxygen concentration in the sweepgas so that no ignition of the biomass would occur $\backslash$ cite $\{$ Joshi2015\}. The conclusions of these experiments were that a small concentration of oxygen has a significant influence on the mass yield which in turn proves to be highly sensitive to the reactor temperature and type of biomass. Joshi et al. (Yash Joshi, 2015) investigated the maximum oxygen concentration at various reactor temperatures of the sweepgas in a packed bed setup at which the energy yield of the solid end product was still acceptable.

Other studies focused on the after treatment of the torrefied product which was produced in an oxidative environment (P. Rousset, 2012)

Chen et al. (Wei-Hsin Chen, 2013) have conducted experiments with varying superficial air velocities. They came to the conclusion that the higher the airflow, the lower the solid yield. However, in their situation they found an upper limit of to the air flow after which a higher velocity has no influence whatsoever on the solid yield. They proposed that at this rate the thermal degradation is no longer governed by surface oxidation but by internal mass transport.

They concluded that, while using small quantities of oxygen during torrefaction, the torrefaction process can be accelerated because the supplied oxygen reacts with the emitted torr-gas, which results in a rise in the temperature of the biomass. As a result of this rise, the biomass will degrade at a higher rate and thus produce more torr-gas while shortening the torrefaction time which speeds up the throughput of the installation.

This paper investigates the use of air as a torrefaction control parameter: controlling the temperature of the biomass 
by varying the oxygen concentration in the torrefaction reactor. The experiments will investigate the use of air to control the biomass temperature and its accompanying torr-gas production. By combusting the torr-gas, the heat production can be determined real-time and energy balances can be made.

Process parameters varied are the reactor temperature, air flow and the injection air at different moments in time. This information will enable commercial torrefaction systems to balance the heat production and the heat demand of the torrefaction installation while having a constant torrefaction degree and highest possible product yield.

\section{Method}

The experimental setup is designed to torrefy biomass parts with a maximum diameter of $30 \mathrm{~mm}$. The torrefaction experiments are done with a batch-type reactor, as shown in Figure 1. In the present case, beech wood is used because of its uniform structure and quality as a biomass source for calibration of the test system.

The experimental system consists of two main sections. The lower section is the torrefaction reactor in which a biomass sample material, or a holder with biomass chips or saw dust, can be placed with a maximum diameter of $30 \mathrm{~mm}$ and a length of $200 \mathrm{~mm}$. The temperature in the biomass sample is measured by five type $\mathrm{K}$ thermocouples mounted in the sample, see Figure 2.

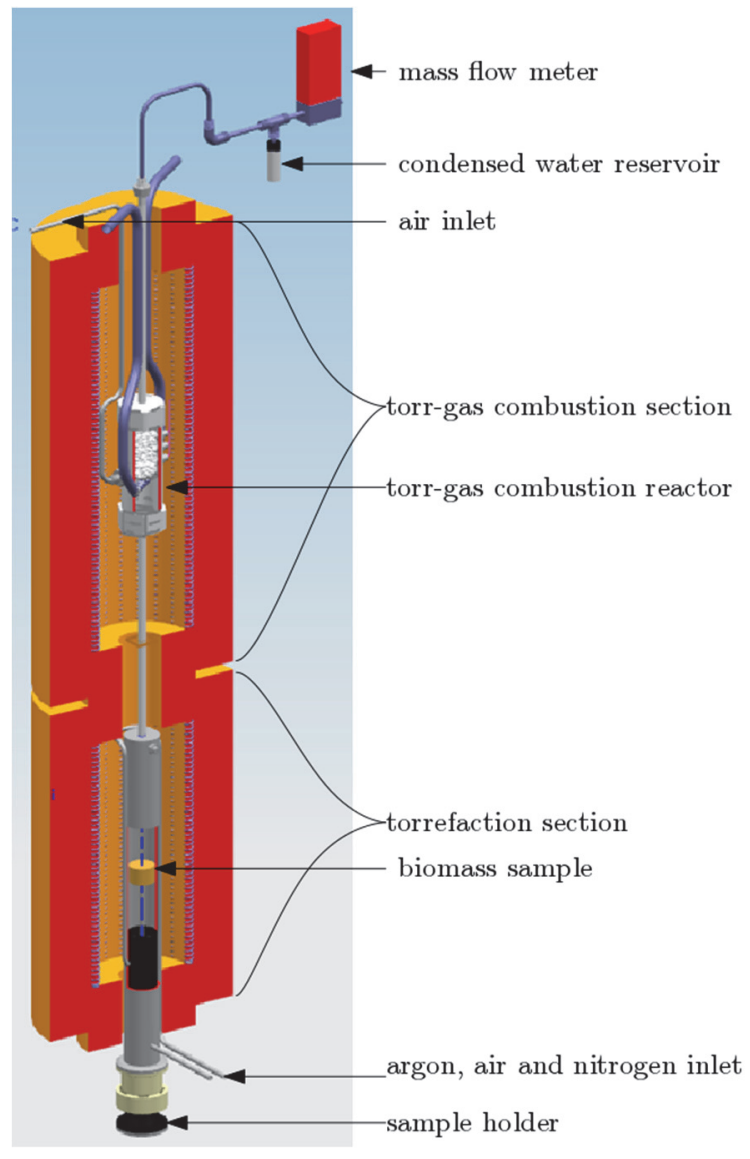

Figure 1. Cross section of the setup
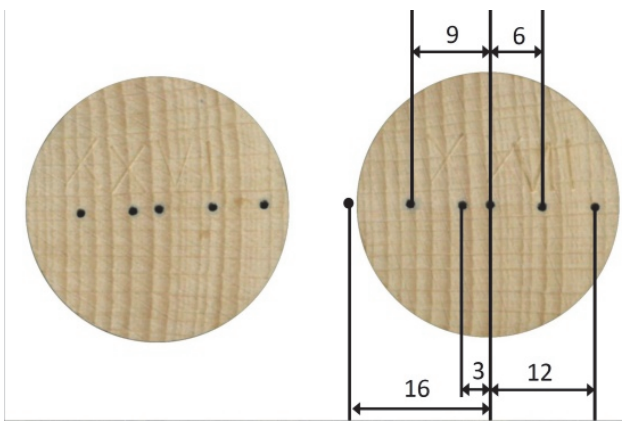

Figure 2. top view of beech wood sample

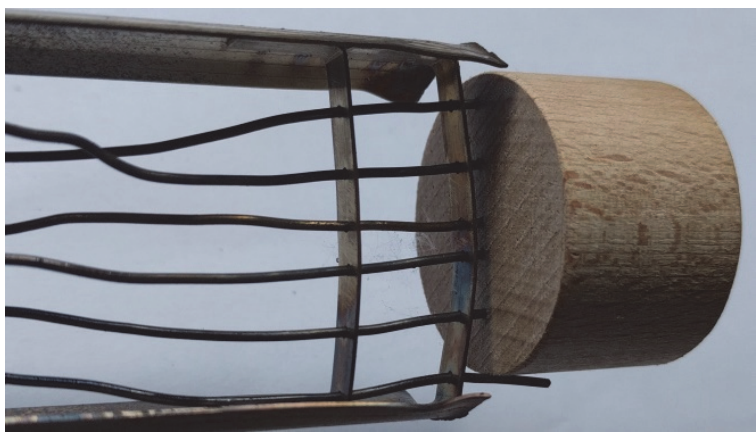

Figure 3. Location of the thermocouples in the sample

A sixth thermocouple is placed just outside the biomass sample to measure the reactor temperature near the sample. These thermocouples are fixed at the bottom of the sample holder and keep the sample in place. The lower reactor is made of stainless steel with a wall thickness of $2 \mathrm{~mm}$. The reactor tube is externally heated by a Carbolic tube furnace with an internal height of $300 \mathrm{~mm}$ and internal width of $120 \mathrm{~mm}$. The reactor tube protrudes $100 \mathrm{~mm}$ outside the oven, which creates a temperature difference of $250^{\circ} \mathrm{C}$ lengthwise the reactor tube. The sample holder can slide in vertical direction inside the torrefaction reactor tube which enables torrefaction experiments in which the temperature around the biomass sample can be changed rapidly. At the bottom of the lower reactor there are three gas connections. One can be used to flush the reactor with preheated argon meant for entrainment of the torrgas. A second inlet is used for nitrogen to rapidly cool down the biomass sample and a third is to supply air, either 
for partial or complete combustion of the sample material. The produced torr-gas is transported through a small pipe into the upper section. The upper section is used to combust the torr-gas. The combustor is externally heated and filled with $5-8 \mathrm{~mm}$ steel spheres coated with catalytic material to distribute the heat generated by the combustion of the torr-gas. Pre-heated air is supplied at the bottom of the glass spheres where it is mixed with torrgas. The temperature of the combustion bed is monitored by two thermocouples of which the lower thermocouple is located $15 \mathrm{~mm}$ above the preheated air inlet. The second thermocouple is placed at a distance of $15 \mathrm{~mm}$ above the lower thermocouple to monitor the heat distribution throughout the combustion bed. The off-gas exits the combustor at the top where the gas is cooled down and the condensed water vapour is collected. After the water collection, the exhaust gas enters a mass flow meter to determine the total flow. It is possible to combust the torrgas including the tar components at relatively low temperatures of $520^{\circ} \mathrm{C}$. Due to the combustion of torr-gas, the temperature of the combustion bed will rise at a rate depending on the instantaneous heat-production in the combustion process and the heat-release of the combustion reactor to the surroundings. To link the temperature rise or drop of the combustion bed to the quantitatively real time calorific value of the ablated off-gas during torrefaction, the combustion bed needs to be calibrated with a known (constant) heat source. This can be a combustible gas or, as in our case, a heating coil supplied with a constant voltage and current during a specified period of time.

\subsection{Calibration of the Combustor}

As indicated in the previous paragraph, heat is supplied to the combustion chamber at preset values of the power but constant for certain chosen periods of time. The heat is generated by an electric heating coil located at the bottom of the combustion bed and is made from an iron-chromium-aluminium (kanthal) alloy. The generated heat is transported by the argon sweepgas through the combustion bed, see Figure 4.

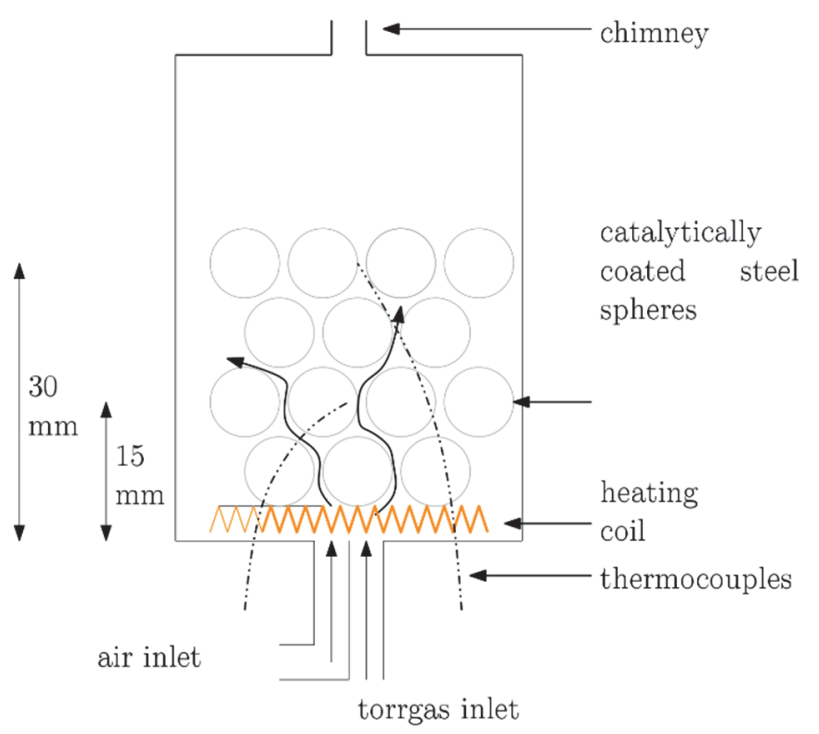

Figure 4. Cross section of the torr-gas combustion section with the location of the thermocouples

The calibration procedure and its accompanying mathematical proof is explained in detail in an earlier paper (Z.C. Bourgonje, 2017). The outcome of the calibration procedure is that the temperature rise of the combustion bed due to a heat source can be converted to the thermal power by using the following formula:

$$
P(t)=\frac{C}{\alpha}\left[T(t)+\tau \frac{d T(t)}{d t}\right]
$$

in which $P(t)$ is the calculated thermal power, $T(t)$ is the temperature of the combustion bed minus the steady state reactor temperature and the $\alpha$ and $\tau$ are the constants determined by the calibration procedure. $\alpha$ is a constant correction factor between the temperature rise and the applied thermal power (in this case the heating coil) and the $\tau$ is the response time. By calibrating the combustor for different constant power levels in the range of the thermal output by combusting the ablated torr-gas it was proven that $\alpha$ and $\tau$ are constant and therefore it is assumed that this formula can also be applied to calculate the thermal power of the ablated torr-gas during torrefaction. 
Unfortunately, not all the heat produced by the heating coil will arrive in the combustion bed above due to radiation and other heat losses. Therefore, a correction factor is added to equation 1 to compensate for this heat loss. The correction factor $\mathrm{C}$ is determined by integrating the power curve of the torr-gas and setting this equal to the difference in higher heating value of two samples (virgin biomass and the torrefied biomass) multiplied by their masses: $m_{A}$ and $m_{B}$ respectively.

$$
C=\frac{m_{A} \cdot H H V_{A}-m_{A B} \cdot H H V_{B}}{\int_{t_{A}}^{t_{B}} P(t) d t}
$$

Since a bomb calorimeter measurement is costly, the higher heating value of the samples used in this paper are determined using reference values of seven beach wood samples which were torrefied for different residence times in the reactor. It was found in (Congwei Wang, 2013) and (P. Rousset, 2012) that the energy yield of the torrefied biomass is essentially determined by the mass yield and not whether there is $\mathrm{O}_{2}$ present in the sweepgas. In Figure 5 , a polynomial fitting curve was applied to the tested samples and with this fitting in combination with the mass loss of the samples used in the oxidative torrefaction experiments described in the following sections the higher heating value was determined.

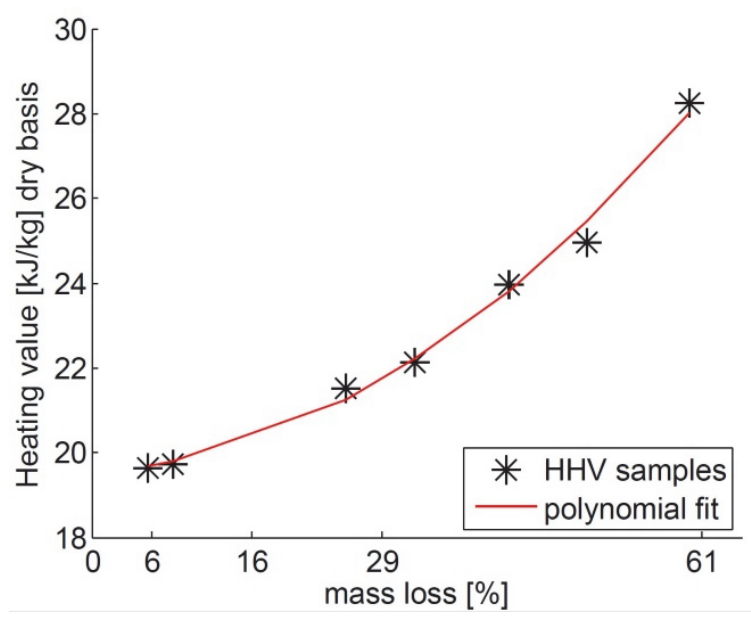

Figure 5. Higher Heating Value of torrefied beech wood as function of mass loss

\subsection{Torrefaction Procedure}

The experimental test procedure consists of three stages reached by moving the biomass sample in the reactor. First, the biomass sample is placed at the bottom of the torrefaction reactor where the surrounding temperature is $105^{\circ} \mathrm{C}$ so that the physical moisture evaporates, see 错误!未找到引用源。. After the drying stage, the biomass particle is moved upwards in the reactor where the temperature is $200-300^{\circ} \mathrm{C}$. At this temperature, the biomass particles are held for 5-180 minutes depending on the type of measurement and the torrefaction process takes place. The last stage is the rapid cooling down of the torrefied biomass sample. By sliding the biomass sample holder to the bottom of the reactor. The biomass sample is kept in location A till it reaches a temperature of $60^{\circ} \mathrm{C}$. At this temperature the sample will not auto-ignite when it is removed from the reactor and placed in ambient air.

Before the experiments start, both reactors are heated until the pre-set temperature is reached. The lower reactor has an inflow of preheated argon sweepgas with a rate of $17 \mathrm{Nl} / \mathrm{h}$ and in the upper reactor preheated air (T_air $=T_{\text {_combustor }}$ ) is supplied at a flow of $60 \mathrm{Nl} / \mathrm{h}$. 

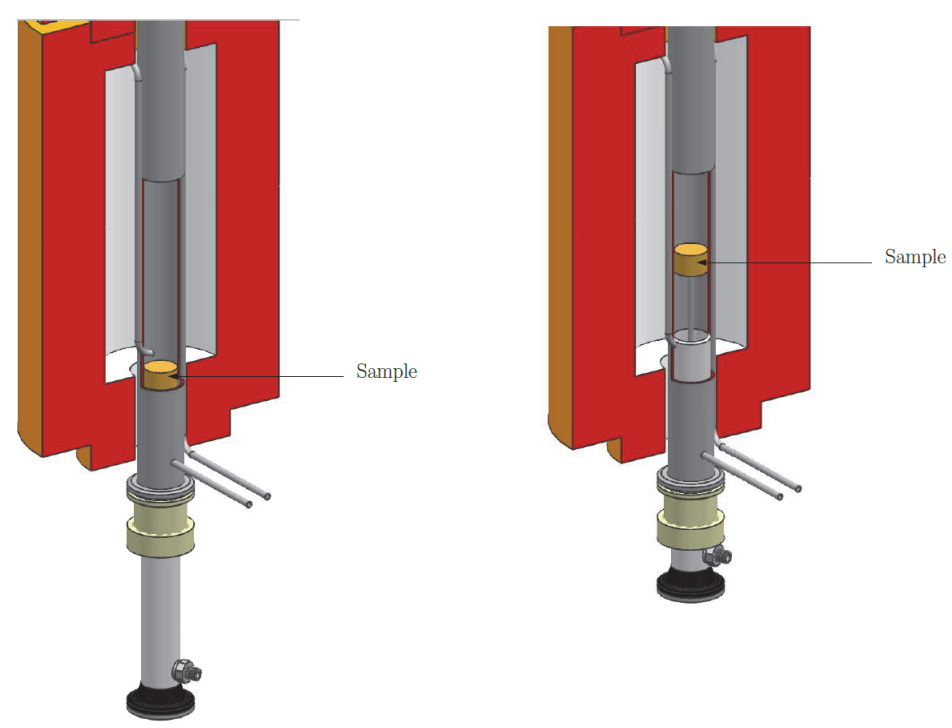

Figure 6. Sample locations during experiment. left: drying location A, right: torrefaction location B

To determine the influence of air on the torrefaction process, three different types of experiments were conducted:

1. The influence of varying the reactor temperature in the presence of air: 245,284 and $313^{\circ} \mathrm{C}$ while the air flow and argon flow are kept constant at $4.4 \mathrm{Nl} / \mathrm{h}$ and $17 \mathrm{Nl} / \mathrm{h}$ respectively.

2. Varying the amount of air: the reactor temperature is kept constant at $265^{\circ} \mathrm{C}$ and the argon flow of 17 $\mathrm{Nl} / \mathrm{h}$. Only the airflow is varied: no flow, 4.4 and $11.1 \mathrm{Nl} / \mathrm{h}$.

3. Adding air at different moments during the torrefaction. Here the reactor temperature is kept constant at $254^{\circ} \mathrm{C}$ for the 3 experiments and the only difference is the moment at which the air flow of $74 \mathrm{ml} / \mathrm{min}$ is added to the preheated argon flow. The three points in time of this adding of air are:

a) Air supply far after the sample has reached its maximum temperature

b) Air supply just after the sample has reached its maximum temperature

c) Air supply from the start of the torrefaction experiment

In the following paragraph the three experiments and their results are presented along with the discussion.

\section{Results}

\subsection{First Set of Experiments: Different Temperature and Constant Oxygen Supply}

In the first set of the experiments, only the torrefaction temperatures are different and all other parameters are kept constant. To keep the conditions in the torr-gas combustion reactor constant for all three experiments, the temperature of the torrefaction oven is the same for all three experiments $\left(@ 350^{\circ} \mathrm{C}\right)$. Because of the temperature gradient over the length of the torrefaction reactor, the different torrefaction temperatures are obtained by varying the position of the biomass sample.

In Figure 7 the data of the experiments are plotted. In the upper figure the power produced by combustion of the torr-gas is displayed for all three experiments $\left(\mathrm{P}_{\mathrm{A}}, \mathrm{P}_{\mathrm{B}}\right.$ and $\left.\mathrm{P}_{\mathrm{C}}\right)$. The total power is determined by integrating the power curves for each sample $\left(\mathrm{Q}_{\mathrm{A}}, \mathrm{Q}_{\mathrm{B}}\right.$ and $\left.\mathrm{Q}_{\mathrm{C}}\right)$ over 50 minutes. In the lower figure the recorded temperatures of the biomass sample are shown. The thermocouples are placed at the core $(\mathrm{r}=0 \mathrm{~mm})$ and at the surface of the biomass sample $(\mathrm{r}=16 \mathrm{~mm})$. 


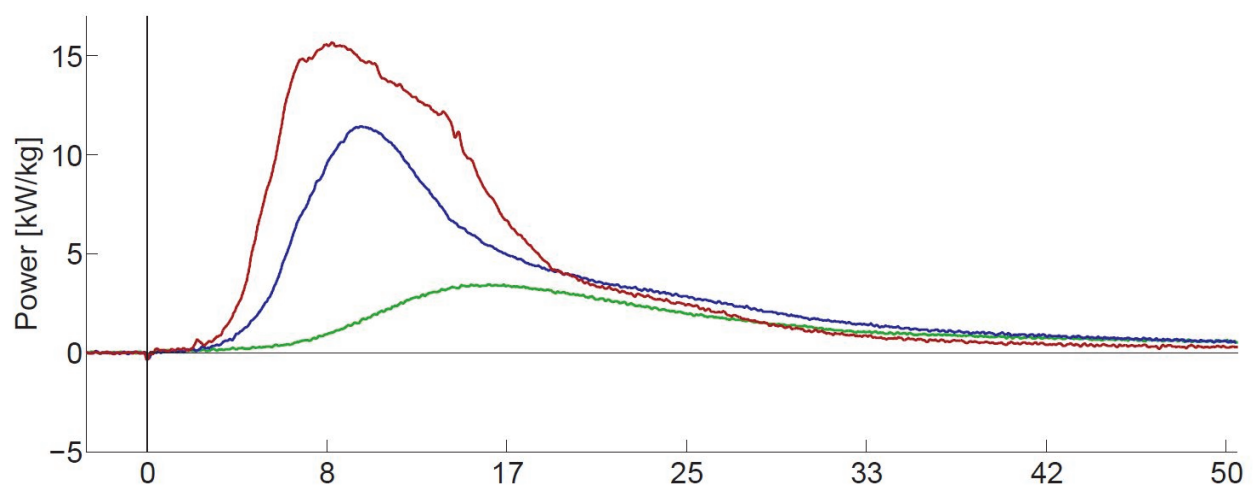

$$
\begin{aligned}
& -\mathrm{P}_{\mathrm{A}} 245^{\circ} \mathrm{C} \\
& -\mathrm{P}_{\mathrm{B}} 284^{\circ} \mathrm{C} \\
& -\mathrm{P}_{\mathrm{C}} 313^{\circ} \mathrm{C}
\end{aligned}
$$
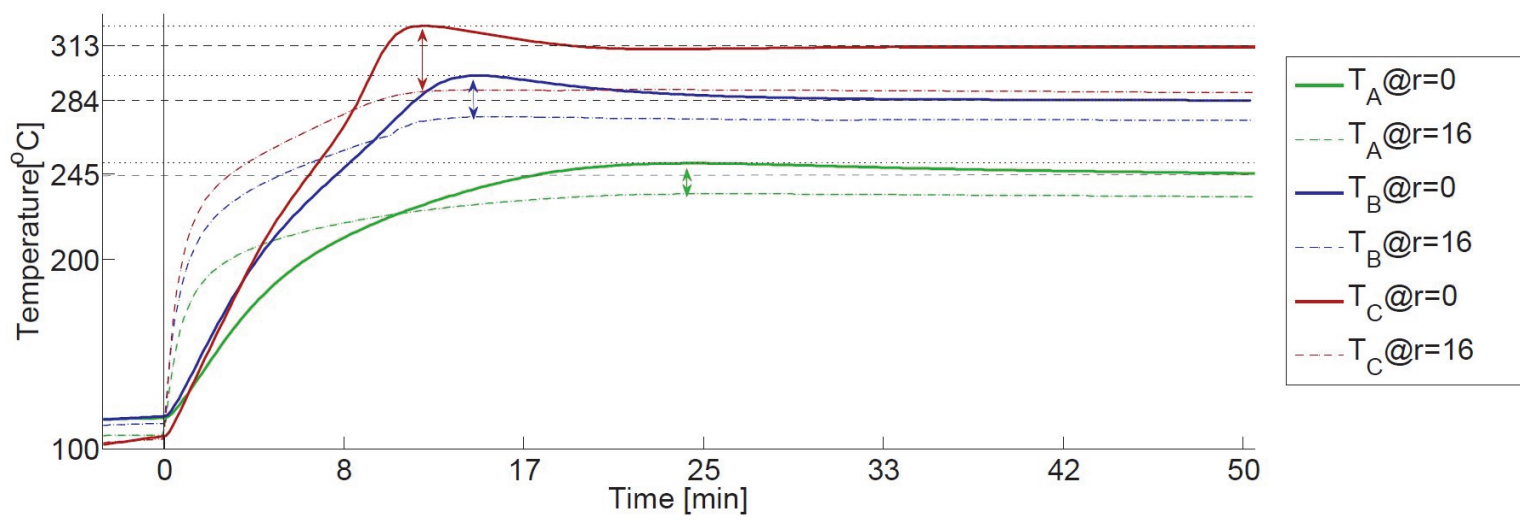

Figure 7. Power of torr-gas combustion and temperature of the biomass samples for the torrefaction experiments with different torrefaction temperatures

As expected, the higher the torrefaction temperature, the faster the heating-up of the sample and the higher the total torr-gas yield. For a torrefaction temperature of $313^{\circ} \mathrm{C}$ the production peak is six times as high, but much narrower in time compared to the $245^{\circ} \mathrm{C}$ reactor temperature experiment. The horizontal dashed black lines represent the maximum temperature of each sample measured at the center $\left(\mathrm{T}_{\text {sample, max }}\right)$. The distance between the horizontal grey dotted and dashed lines in the lower graph represents the exothermic overshoot of the temperature at the core of the sample ( $\mathrm{T}_{\text {overshoot }}$ ) above the final stable temperature. The double arrows show the maximum temperature gradient between the core and the surface of the sample $\left(\Delta \mathrm{T}_{\text {sample }}\right)$.

When torrefying at low temperatures like $245^{\circ} \mathrm{C}$, the exothermic reaction is less strong than when torrefying at $313^{\circ} \mathrm{C}$. The exothermic reaction is more spread out in time however. Another observation is that for the $284^{\circ} \mathrm{C}$ and $313^{\circ} \mathrm{C}$ experiments, the combustion power curve is much wider. This was also observed in (Ajmia Chouchene M. J., 2010) and could be due to the degradation of hemicellulose and decomposition of cellulose according to (M.C Blanco Lopez, 2002) and (J.J.M. Orfão, 1999). In table 1 the results of this set of experiments are summarized.

Table 1. Overview first set of experiments varying $\mathrm{T}$

\begin{tabular}{|c|c|c|c|}
\hline Sample & A & B & $\mathrm{C}$ \\
\hline \multicolumn{4}{|l|}{ Photograph top sample } \\
\hline $\mathrm{T}_{\text {sample max }}$ at $\mathrm{r}=0 \mathrm{~mm}\left[{ }^{\circ} \mathrm{C}\right]$ & 251 & 297 & 323 \\
\hline $\mathrm{T}_{\text {reactor }}\left[{ }^{\circ} \mathrm{C}\right]$ & 245 & 284 & 313 \\
\hline
\end{tabular}




\begin{tabular}{llll}
\hline $\mathrm{T}_{\text {overshoor }}$ at $\mathrm{r}=0 \mathrm{~mm}\left[{ }^{\circ} \mathrm{C}\right]$ & 6 & 13 & 10 \\
$\Delta \mathrm{T}_{\text {sample }}\left[{ }^{\circ} \mathrm{C}\right]$ & 16.0 & 21.7 & 33.6 \\
Q produced the first 50 minutes [MJ/kg] & 4.25 & 9.27 & 11.9 \\
Solid mass yield [\%] a.r. & 68 & 50 & 37 \\
Volume shrink [\%] & 16.4 & 32.2 & 48.2 \\
$\mathrm{O}_{2}$ concentration [\%VOL] & 4.4 & 4.4 & 4.4 \\
\hline
\end{tabular}

\subsection{Second Set of Experiments: Varying Oxygen Flow}

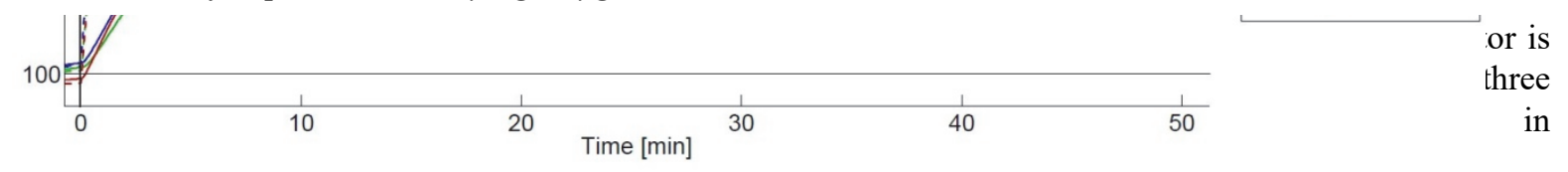

Figure 8, the extra air supply has no significant effect on the heating rate until the biomass reaches a temperature of about $220^{\circ} \mathrm{C}$. This holds good for the thermocouple placed in the centre $(\mathrm{r}=0)$ as well as for the thermocouple placed at the edge of the sample $(\mathrm{r}=12 \mathrm{~mm})$. When the samples reach $250^{\circ} \mathrm{C}$, the samples to which air is supplied (E, F) have a higher heating rate than sample D to which no air is supplied. This was also observed in the TGA experiments done by Fang et al. (M.X. Fang, 2006).

This addition of air also has a very strong effect on the maximum temperature of the sample at $r=0$. In the case of sample F, the sample temperature rises faster than that of the samples D and E. This results in large cracks in the sample, see the photograph of sample $\mathrm{F}$ in table 2 . The solid yield decreased significantly due to the use of oxygen when compared to sample A which was torrefied in a pure argon flow. The solid yield decrease was also observed in the experiments done by Tran et al. (Khanh-Quang Tran, 2016) but is much smaller in their experiments. A likely explanation for this is that because their biomass particles were much smaller $(3-4 \mathrm{~mm})$, the heat exchange rate with the surroundings was much higher resulting in lower peak temperatures.
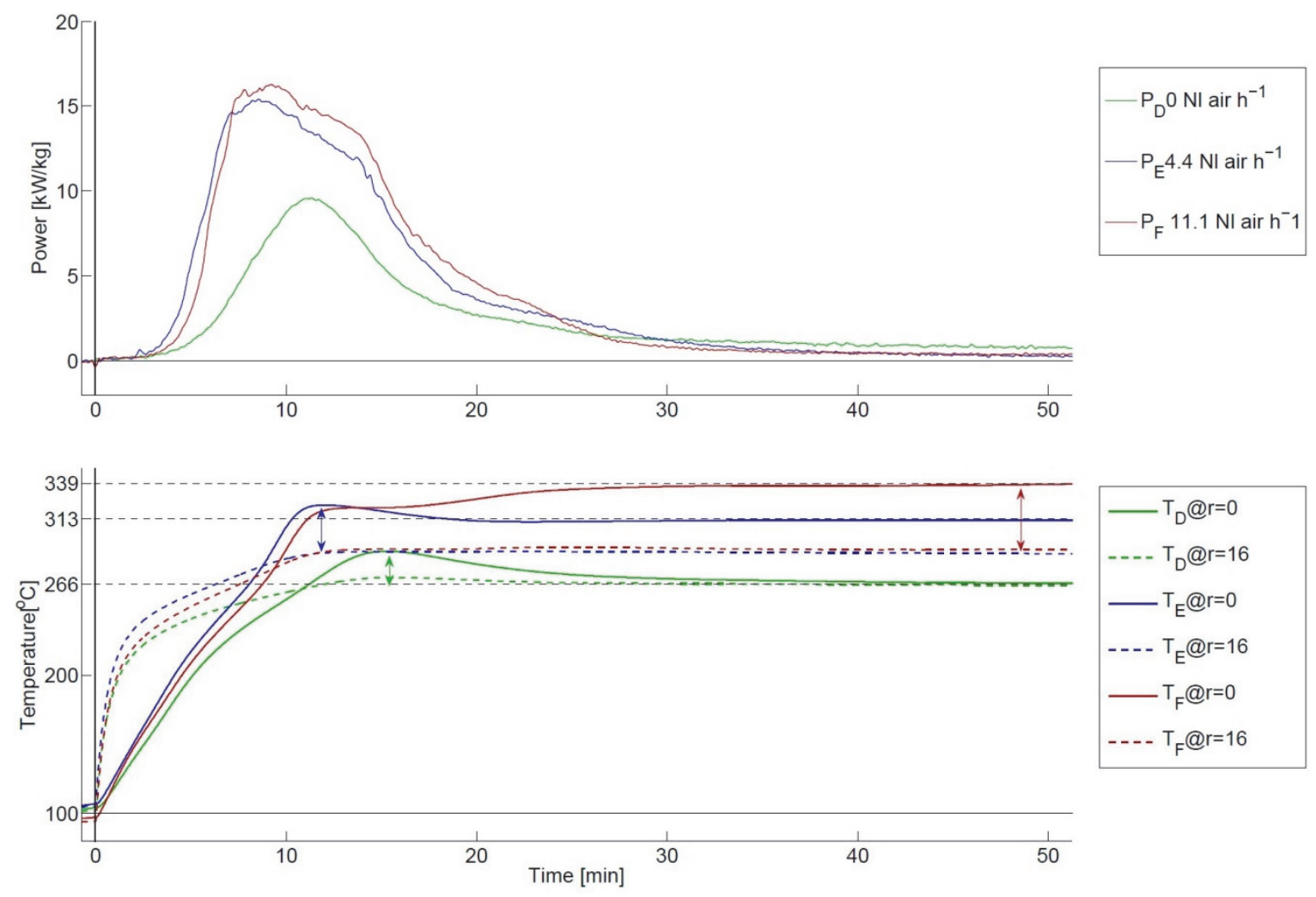

Figure 8. Influence of air supply on the temperature of the samples during torrefaction and the accompanying thermal power by combusting the torr-gas 


\begin{tabular}{rrrrrr}
\hline & 1 & 1 & 1 & 1 \\
0 & 10 & 20 & Time [min] & 30 & 40
\end{tabular}

in

Figure 8 is that the temperature gradient between the core and the outside of the sample is different for the samples $\mathrm{E}$ and $\mathrm{F}$ compared to sample D. In the case where no oxygen is supplied to the reactor, the core and surface temperature of the sample are even after 40 minutes in the reactor. This is however not the case for the samples $\mathrm{E}$ and F. It can be concluded that the oxygen molecules can travel to the core of the sample and react with the emitted torr-gas which result in a local heat production.

Table 2. Overview second set of experiments varying airflow

\begin{tabular}{llll}
\hline Sample & $\mathrm{D}$ & Patograph top sample & \\
\hline Phot
\end{tabular}

\begin{tabular}{llll}
\hline Air flow $[\mathrm{Nl} / \mathrm{h}]$ & 0 & 4.4 & 11.1 \\
\hline $\mathrm{T}_{\text {sample max }}$ at $\mathrm{r}=0 \mathrm{~mm}\left[{ }^{\circ} \mathrm{C}\right]$ & 290 & 323 & 339 \\
\hline $\mathrm{T}_{\text {reactor }}\left[{ }^{\circ} \mathrm{C}\right]$ & 265 & 265 & 265 \\
\hline $\mathrm{T}_{\text {overshoor }}$ at $\mathrm{r}=0 \mathrm{~mm}\left[{ }^{\circ} \mathrm{C}\right]$ & 25.0 & 10.1 & 0.8 \\
\hline$\Delta \mathrm{T}_{\text {sample }}\left[{ }^{\circ} \mathrm{C}\right]$ & 19.1 & 33.6 & 47.4 \\
\hline Q produced the first 50 minutes $[\mathrm{MJ} / \mathrm{kg}]$ & 7.37 & 11.82 & 12.26 \\
\hline Solid mass yield [\%] a.r. & 61 & 37 & 31 \\
\hline Volume shrink [\%] & 20.9 & 48.2 & 54.7 \\
\hline $\mathrm{O}_{2}$ concentration [\%VOL] & 0 & 4.4 & 8.3 \\
\hline
\end{tabular}

\subsection{Third Set of Experiments: Adding Oxygen at Different Moments in Time}

In Figure 9 and table $\backslash$ ref $\{$ table 2$\}$ the data are shown for the experiment in which an air flow of $4.4 \mathrm{Nl} / \mathrm{h}$ was added at three different moments. Sample $G$ has the airflow from the beginning. For sample H, the air was added after 17 minutes to the reactor and for sample I the air was added after 42 minutes to the reactor.

The experiment with sample $\mathrm{G}$ is done to see whether the torrefaction process could be accelerated by adding air: the air flow was added during the drying stage whereas for samples $\mathrm{H}$ and I there was only the argon flow. When looking at the drying stage of the samples in the cold zone, sample $\mathrm{G}$ has a higher heating rate than those of samples $\mathrm{H}$ and I. This is also true for the torrefaction stage and when looking at the heat produced by combustion of the torr-gas, the production rate is higher than that of samples $\mathrm{H}$ and $\mathrm{I}$.

For sample $\mathrm{H}$, the airflow is added for a period of 197 minutes after the torr-gas production has reached its maximum (blue lines in Figure 9). The 17 minutes was chosen to see whether the torr-gas production could be enhanced with air when the torr-gas production is already declining. The airflow causes a temperature rise of the sample due to combusting the torr-gas in the vicinity of the sample. Due to this rise in temperature, the torr-gas production rate becomes higher until the volatiles in the sample are exhausted (more about this in the discussion). The small peak and following dip in the torr-gas production rate for sample $\mathrm{H}$ which can be seen in the upper part of Figure $\backslash$ ref \{third\} is caused by the air mass flow controller which needs a couple of seconds after switching on before the air flow reaches the set point. The experiment with sample I was held to see whether air could still enhance the torr-gas production when the sample was almost completely exhausted of volatiles (red lines in Figure 9). 

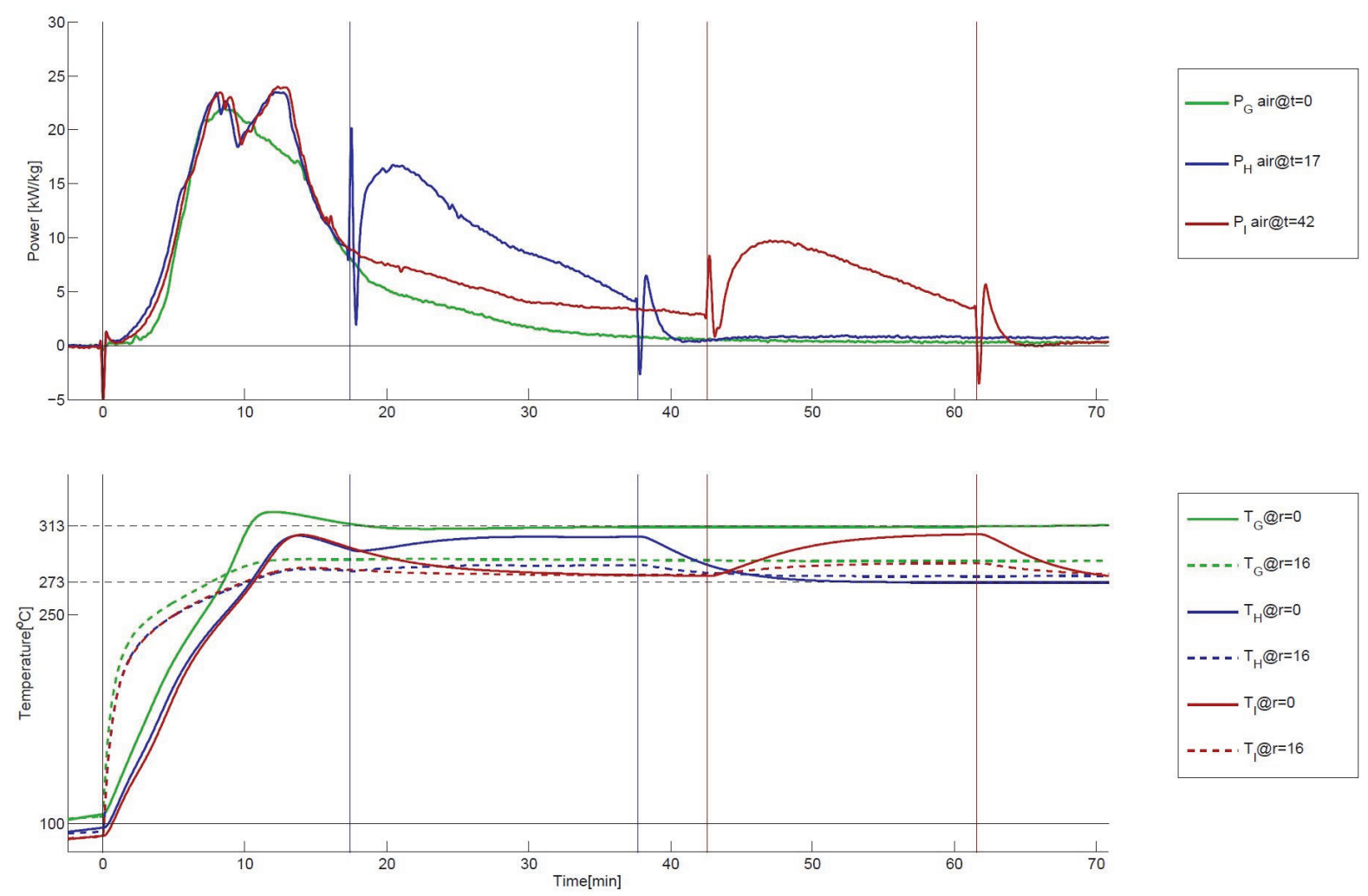

Figure 9. Power and Temperature profiles for air supply at different moments in time

Table 3. Overview third set of experiments varying airflow in time

\begin{tabular}{llll}
\hline Sample & $\mathrm{G}$ & $\mathrm{H}$ & $\mathrm{I}$ \\
\hline Photograph top sample & & & \\
& & & \\
& & & \\
& & & \\
& & & \\
\hline Air flow of $4.4 \mathrm{Nl} / \mathrm{h}$ after time $[\mathrm{min}]$ & 0 & 306 & 307 \\
\hline $\mathrm{T}_{\text {sample max }}$ at $\mathrm{r}=0 \mathrm{~mm}\left[{ }^{\circ} \mathrm{C}\right]$ & 323 & 265 & 265 \\
\hline $\mathrm{T}_{\text {reactor }}\left[{ }^{\circ} \mathrm{C}\right]$ & 265 & 21.0 & 20.6 \\
\hline$\Delta \mathrm{T}_{\text {sample }}\left[{ }^{\circ} \mathrm{C}\right]$ & 33.6 & 12.17 & 11.60 \\
\hline $\mathrm{Q}$ produced the first 50 minutes $[\mathrm{MJ} / \mathrm{kg}]$ & 12.15 & 46 & 44 \\
\hline Solid mass yield $[\%]$ a.r. & 37 & 46 & 44 \\
\hline Volume shrink [\%] & 37 & $0 \& 4.4$ & $0 \& 4.4$ \\
\hline $\mathrm{O}_{2}$ concentration $[\% \mathrm{VOL}]$ & 4.4 & & \\
\hline
\end{tabular}

Summarizing the results of the three experiments, the torr-gas production rate can be raised or lowered by injecting a small flow of air during the torrefaction process. The adding of air leads to a higher sample core temperature when the air is added at the start of the torrefaction process compared to the samples where air was added after 17 
and 42 minutes. When looking at the produced thermal heat Q in table Table 3, the amount of thermal heat Q does not change significantly whether the air is injected at the start of the torrefaction experiment (sample G), after 17 minutes (sample H), or at the end (sample I).

\section{Discussion}

The discussion consists of two sections. The first part considers the increasing temperature gradient measured between the core and the outer surface of the biomass sample when adding oxygen to the argon sweepgas. The second part explains how this addition of air can be used to rapidly control the biomass bed temperature in large scale torrefaction systems.

\subsection{Influence of Air on the Temperature Gradient Measured in the Biomass Sample}

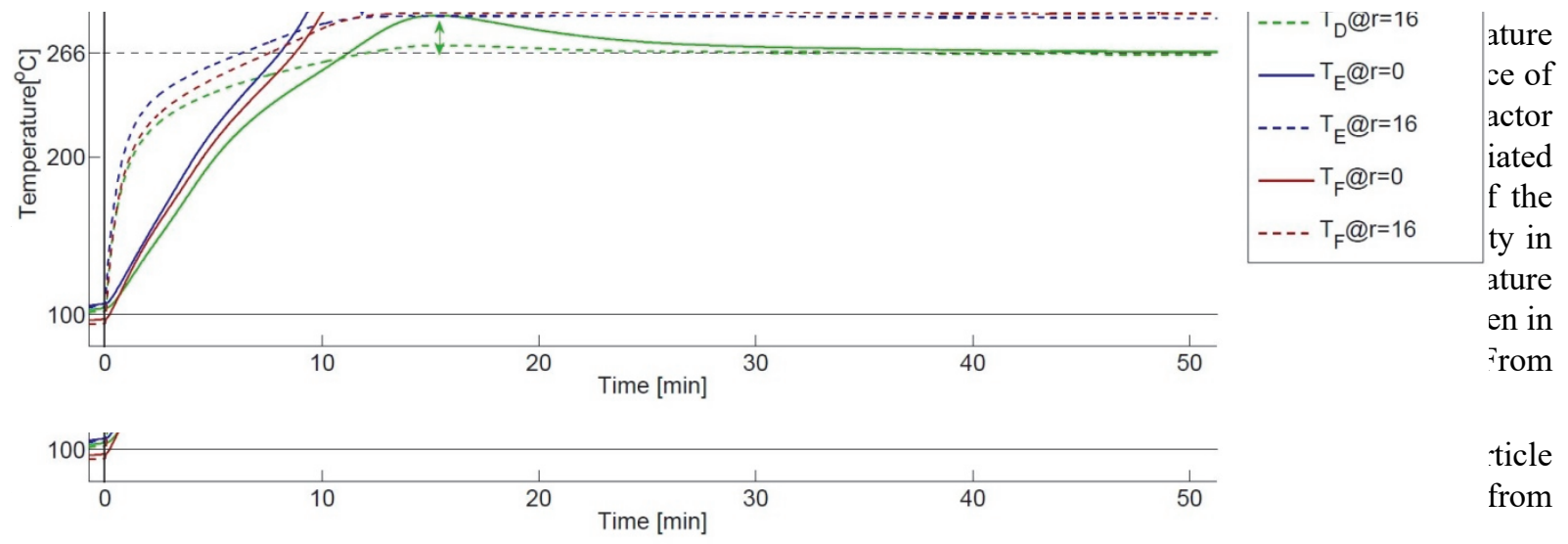

Figure 8 where respectively a flow 4.4 and $11.1 \mathrm{Nl} / \mathrm{h}$ air was supplied, the temperature gradient between the core and the outer surface of the sample was 25 and 48 degrees.

A likely explanation for this increasing temperature gradient with increasing oxygen concentration in the sweepgas is that the oxygen can travel freely though the biomass structure. To see if the pores inside the torrefied wood are large enough to let air molecules pass, an X-ray computed tomography experiment was held by Nefkens (Nefkens, 2016) to determine the average pore size. Both the virgin wood and the excessively torrefied wood were tested to determine the change in poor size distribution of the biomass sample.

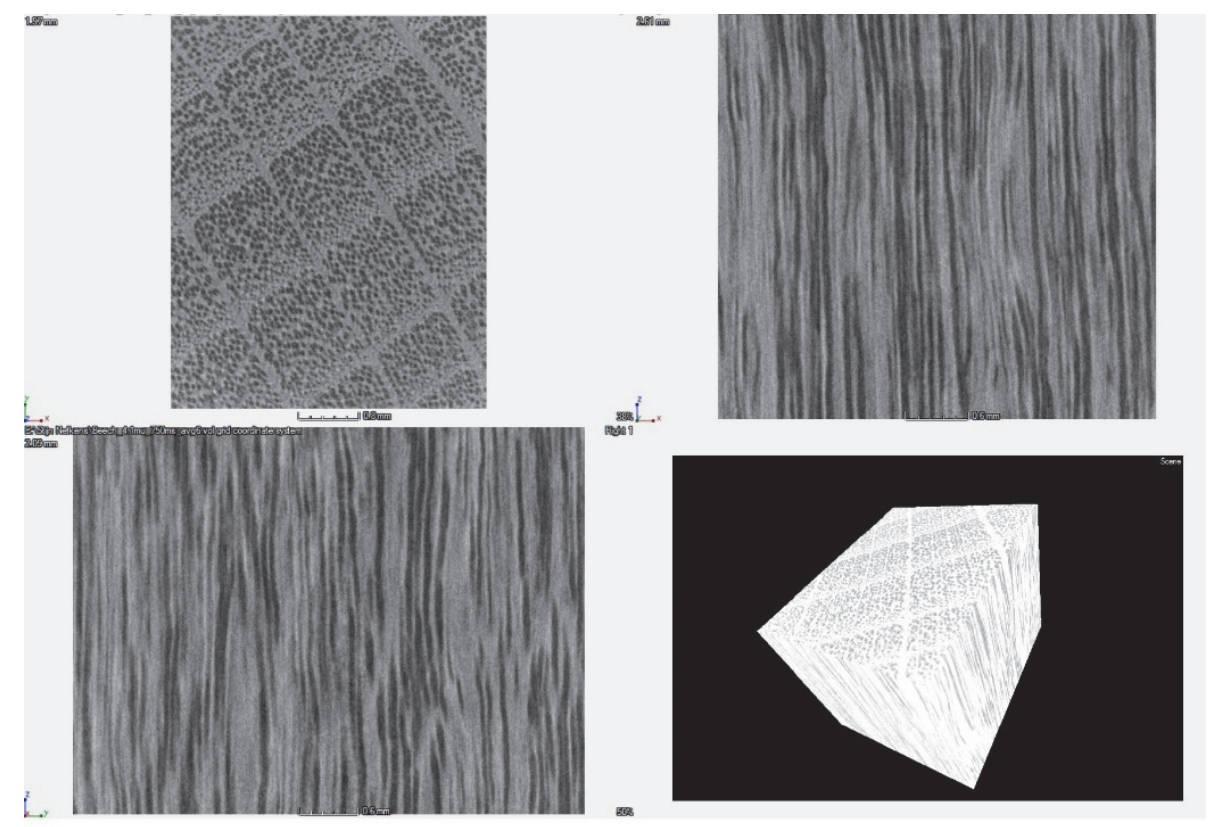

Figure 10. Density profiles of cross-sections of beech in three directions and a 3D image of the isolated volume; darker areas indicate lower density 


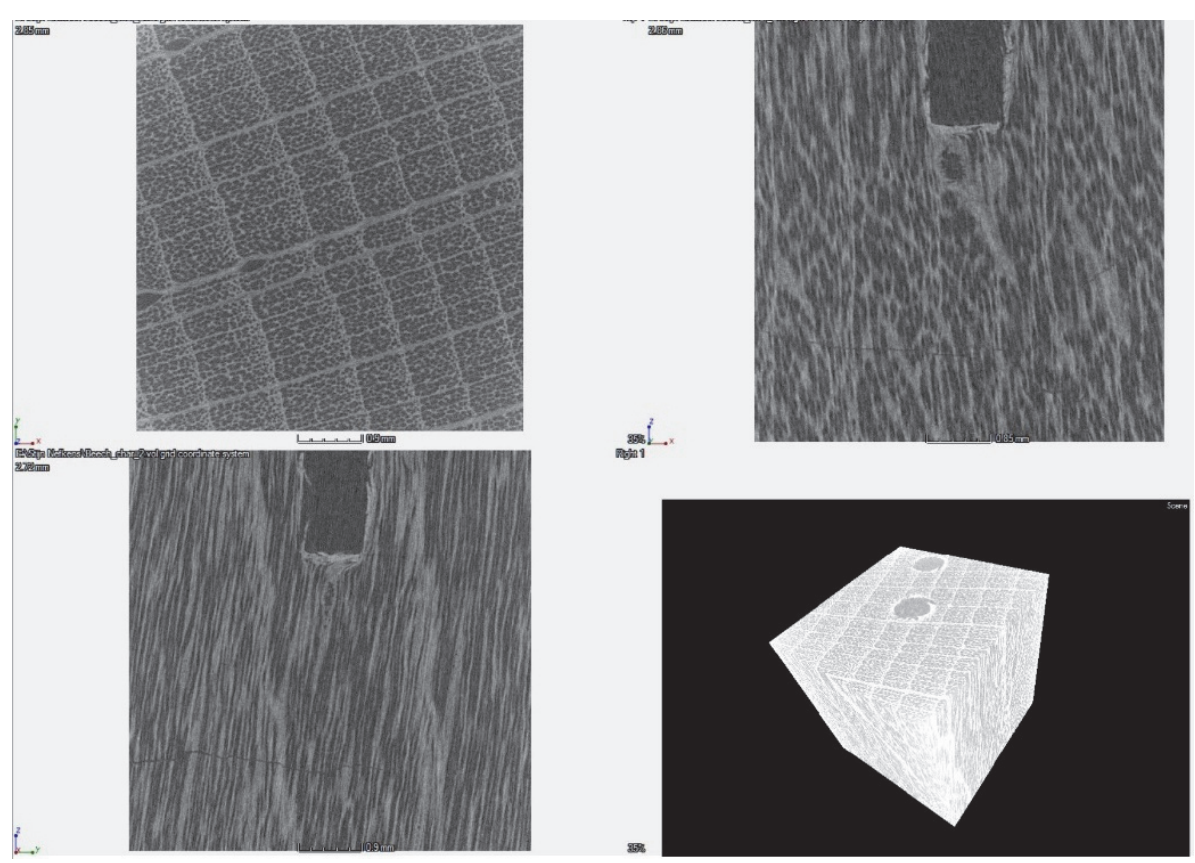

Figure 11. Density profiles of cross-sections of torrefied beech in three directions and a 3D image of the isolated volume; darker areas indicate lower density

Figure 12 shows the distribution of pore sizes for both the virgin biomass and the torrefied biomass. As expected from the material shrinkage, the average pore radius becomes smaller for torrefied material. When the mean free path of the oxygen molecule is calculated it can be seen that those molecules can travel freely through the biomass sample because the mean free path at ambient pressure and $300^{\circ} \mathrm{C}$ is much smaller than that of the pores in the biomass: $75 \mathrm{~nm}$ versus 30 micron. The overall conclusion is then that there is a competition of two effects: $\mathrm{O}_{2}$ can diffuse into the particle, but the torr-gas production causes an outward flow which pushes the gasses out.

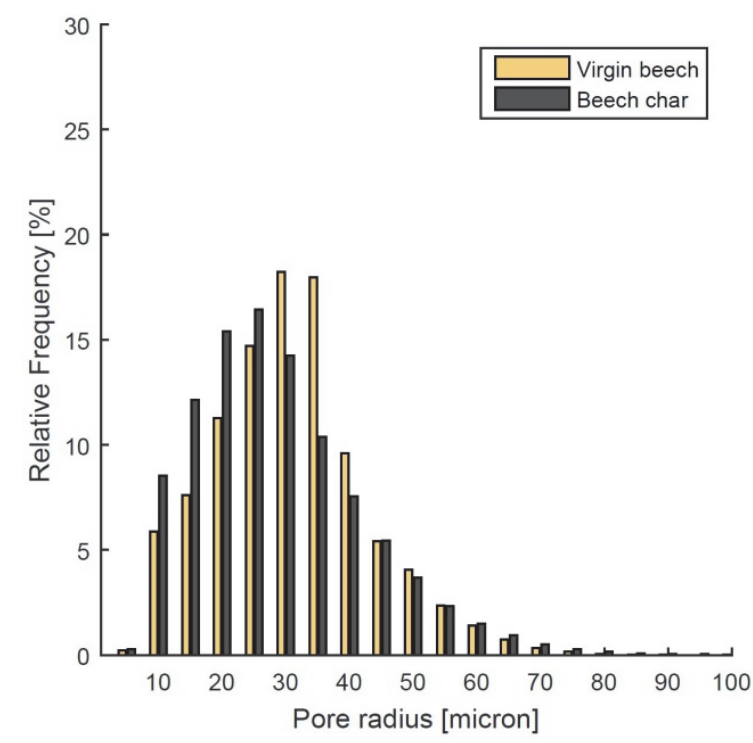

Figure 12. Histogram of the pore size distribution in micron obtained by post processing of the X-ray scans 
The adding of air to control the temperature of the biomass in large scale torrefaction reactors might solve the difficulty to process varying biomass types and qualities (e.g. moisture content) which causes fluctuations in the torr-gas production and the heat demand of the biomass itself. Especially in auger or rotating drum reactors, the torrefaction process control can benefit from having multiple air inlets along the reactor in horizontal direction so that air can be injected when the biomass reaches the temperature at which the torr-gas production is at its maximum (adding air when the biomass is too low in temperature only results in combustion of the torr-gas above the torrefaction bed further along the reactor and is thus less effective) or to give an extra temperature boost when the torr-gas production starts. It is thought that small air inlets of around $3 \mathrm{~mm}$ will give a better mixing between the torr-gas and the air resulting in a more homogeneous torrefied end product. From Figure $\backslash$ ref $\{t h i r d\}$ it becomes clear that the torr-gas production can be temporarily increased by adding air. This might be useful in large-scale torrefaction systems when there is an extra heat demand in the dryer, preheater and/or the torrefaction reactor. By adding air, the biomass temperature is slightly raised due to the combustion of the torr-gas in the vicinity of the biomass. Because the torr-gas is partly combusted in the torrefaction reactor, the surplus of torr-gas when combusted can be used in the dryer or in other locations in the torrefaction reactor.

The findings in this publication have led to a patent application (WO Patentnr. WO 2017/133917 A1, 2017) in which the injecting of air into the torrefaction bed is the main feature to either rapidly heat or cool down the biomass in the reactor. The temperature control consists of two independent control mechanisms to improve the temperature variations in the biomass bed due to variations in the feeding material (e.g. a change of moisture content). The first (slow) mechanism is the indirect heating of biomass through a reactor wall. The temperature of the reactor wall is kept at a constant temperature which is the minimum temperature needed at which the biomass produces sufficient quantities of combustible gasses which in combination with oxygen can be used to control the temperature of the biomass. The second (fast) temperature control mechanism is the injecting of small quantities of air below or into the biomass bed. The injected air reacts with the torr-gas and produces heat inside the biomass bed which results in a higher biomass temperature. Since the torr-gas production rate is very sensitive to the biomass temperature, the heat demand of the torrefaction system can be managed.

Figure 13 represents an example of temperature regulation with the three situations which occur in a large scale torrefaction system: normal, heating, and cooling of the biomass inside the reactor. The situation 'normal' is when the temperature of the biomass ( $\left.\mathrm{T}_{\text {target }}\right)$ is sufficient to torrefy the biomass to the desired torrefaction degree while the heat production delivered by combusting the ablated torr-gass is sufficient to run the torrefaction system autothermally. In this situation the flow rate of the injected air into the torrefaction bed is the required flow to raise the biomass temperature from $\left(T_{\text {wall }}\right)$ to $\left(T_{\text {target }}\right)$. The situation 'cooling' is when the biomass temperature rises above the target temperature $\left(\mathrm{T}_{\text {target }}\right)$. In this situation the oxygen flow is reduced or halted and the biomass temperature drops till it reaches $\left(\mathrm{T}_{\text {target}}\right)$. In the situation 'heating', the opposite occurs. The biomass temperature drops below ( $\left.\mathrm{T}_{\text {target}}\right)$ and the oxygen flow is increased by two compared to the 'normal' situation. Due to the larger airflow more torr-gas is combusted inside the biomass bed causing the biomass to rapidly heat up until its temperature reaches its intended target-point and the airflow is reduced to the flow rate of the situation 'normal'.

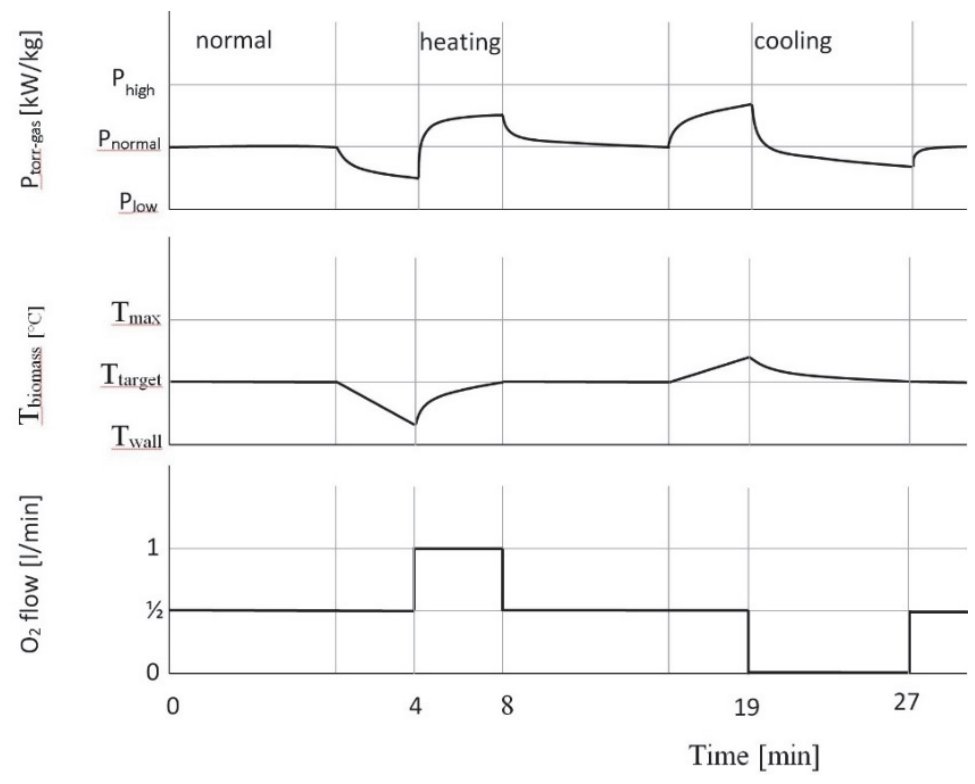


Figure 13. Example of biomass temperature control and torrgas production inside an auger reactor by adding oxygen to the biomass bed

\section{Conclusions}

As expected from the first set of experiments, addition of air at higher torrefaction temperatures results in more torr-gas production together with a lower solid product yield. From the second set of experiments it can be concluded that adding more air from the beginning of the torrefaction process results in a higher biomass sample temperature because of a larger exothermic reaction rate. By adding air, the residence time of the biomass can be reduced as well as the reactor temperature, as was also observed by Wang et al. (Congwei Wang, 2013). From the photograph of the samples (Table 2), it is evident that the airflow is very critical: when too much air is added, the biomass sample starts burning and the sample temperature exceeds the reactor temperature by $73^{\circ} \mathrm{C}$. In this study beech wood samples of 8 grams have been used, but the effect will be much larger in industrial systems which have a throughput of tonnes per hour and this amount of biomass might lead to thermal runaway situations. The third set of experiments shows that it is possible to control the torrefaction process as well as the torr-gas production (to some extent) with a small (varying) amount of air.

Future work will include the development and testing of a small scale continuous screw reactor with a throughput of $50 \mathrm{~kg} / \mathrm{h}$ where nozzles are placed along the length of the reactor which inject air underneath the biomass bed. This new torrefaction temperature control method might be the solution for preventing thermal runaway situation in conventional reactors as well as the foreseen increase of throughput and quality of the torrefied biomass.

\section{References}

Blanco López, M. C., Blanco, C. G., Martínez-Alonso, A., \& Tascón, J. M. D. (2002). Composition of gases released during olive stones pyrolysis. Journal of Analytical and Applied Pyrolysi, 313-322. https://doi.org/10.1016/S0165-2370(02)00008-6

Bourgonje, Z. C., Veringa, H. J.,\& Smeulders, D. M. J. (2017). The new method to characterize the gas emissions during torrefaction real-time. Fuel Processing Technology, 24-32. https://doi.org/10.1016/j.fuproc.2017.04.009

Chen, W. H., Lu, K. M., Liu, S. H., Tsai, C. M., Lee, W. J., \& Lin, T. C. (2013). Biomass torrefaction characteristics in inert and oxidative atmospheres at various superficial velocities. Bioresource Technology, 152-160. https://doi.org/10.1016/j.biortech.2013.07.064

Chouchene, A., Jeguirim, M., Khiari, B., Trouvé, G., \& Zagrouba, F. (2010). Study on the emission mechanism during devolatilization/char oxidation and direct oxidation of olive solid waste in a fixed bed reactor. Journal of Analytical and Applied Pyrolysis, 87(1), 168-174. https://doi.org/10.1016/j.jaap.2009.11.008

Chouchene, A., Jeguirim, M., Khiari, B., Trouvé, G., \& Zagrouba, F. (2010). Thermal degradation of olive solid waste: Influence of particle size and oxygen concentration. Resources, Conservation and Recycling, 271-277. https://doi.org/10.1016/j.resconrec.2009.04.010

Cong wei Wang, C. W., Peng, J. P., Hui Li, H., T.Bi, X. T., Legros, R., Lim, C. J., \& Sokhansanj, S. (2013). Oxidative torrefaction of biomass residues and densification of torrefied sawdust to pellets. Bioresource Technology, 318-325. https://doi.org/10.1016/j.biortech.2012.09.092

Fang, M. X., Shen, D. K., Li, Y. X., Yu, C. J., Luo, Z. Y., \& Cen, K. F. (2006). Kinetic study on pyrolysis and combustion of wood under different oxygen concentrations by using TG-FTIR analysis. Journal of Analytical and Applied Pyrolysis, 22-27. https://doi.org/10.1016/j.jaap.2005.12.010

Joshi, Y. V. (2015). Torrefaction of herbaceous biomass - a study of product, process and technology. Delft: Delft University of Technology. https://doi.org/10.4233/uuid:9990f14d-262c-4247-acd8-a2cb0284f129

Joshi, Y., Marcello, M. D., Krishnamurthy, E., \& de Jong, W. (2015). Packed-bed torrefaction of bagasse under inert and oxygenated atmospheres. Energy \& fuels, 5078-5087. https://doi.org/10.1021/acs.energyfuels.5b00779

Khanh-Quang, T., Trung, N. T., \& Quang-Vu, B. (2016). Development of a biomass torrefaction process integrated with oxy-fuel combustion. Bioresource Technology, 408-413. https://doi.org/10.1016/j.biortech.2015.08.106

Nefkens, S. J. (2016). Modelling the torrefaction of a large biomass particle. Eindhoven: Eindhoven University of Technology.

Orfão, J. J. M., Antunes, F. J. A., \& Figueiredo, J. L. (1999). Pyrolysis kinetics of lignocellulosic materials - three independent reactions model. Fuel, 349-358. https://doi.org/10.1016/S0016-2361(98)00156-2 
Richard, B. B., \& Ahmed, F. G. (2014). Modeling kinetics-transport interactions during biomass torrefaction: The effects of temperature, particle size, and moisture content. Fuel, 216-229. https://doi.org/10.1016/j.fuel.2014.07.047

Rousset, P., Macedo, L., Commandré, J. M., \& Moreira, A. (2012). Biomass torrefaction under different oxygen concentrations and its effect on the composition of the solid by-product. Journal of Analytical and Applied Pyrolysis, 86-91. https://doi.org/10.1016/j.jaap.2012.03.009

Saadon, S., Uemura, Y., \& Mansor, N. (2014). Torrefaction in the Presence of Oxygen and Carbon Dioxide: The Effect on Yield of Oil Palm Kernel Shell. Procedia Chemistry, 194-201. https://doi.org/10.1016/j.proche.2014.05.023

Uemura, Y., Omar, W., Othman, N. A., Yusup, S., \& Toshio, T. (2013). Torrefaction of oil palm in the presence of oxygen. Fuel, 156-160. https://doi.org/10.1016/j.fuel.2011.11.018

Varsheta, S., Yoshimitsu, U., Suhaimi, H., Mohammad, H. S., \& Man, K. L. (2016). Torrefaction of Empty Fruit Bunch in the Presence of Combustion Gas. Procedia Engineering, 750-757. https://doi.org/10.1016/j.proeng.2016.06.608

Zeger Cornelis Bourgonje, W. J. (2017). WO Patent No. WO 2017/133917 A1.

\section{Copyrights}

Copyright for this article is retained by the author(s), with first publication rights granted to the journal.

This is an open-access article distributed under the terms and conditions of the Creative Commons Attribution license (http://creativecommons.org/licenses/by/4.0/). 